\title{
HORIZONS
}

\section{RIGHT TO CARE}

It is strikingly obvious that today's problems cannot be solved with yesterday's solutions and that the HIV epidemic cannot be managed by 'business-as-usual' approaches.

The magnitude of the HIV crisis in Southern Africa and its seemingly unattainable treatment solutions, for which 'Access' has almost become an anathema, desperately needs new, innovative and realistic solutions.

The International AIDS Conference in July and recent IAPAC Resource Allocation for HIVIAIDS and Other Life-threatening IIInesses conference in Cairo (16 - 18 October 2000) only served to highlight the plight of our region and presented few solutions.

Fascinating insights into the global economics surrounding the disease were also presented in a keynote address by Jeffrey Sachs, Director of the Harvard Institute for International Development, who believes that the required 10 -fold increase in annual global AIDS funding (from the current estimate of approximately 500 million US dollars to 5 billion dollars), is very feasible, given the multi-trillion dollar economies of the USA and other industrialised world countries. Sachs recommended a comprehensive global approach, which would have four major elements: adequate financial support, global strategy, global co-ordination and mobilisation of government support; and emphasised that much more careful co-ordination of funding and resources is critical.

In our region of the world, we remain overwhelmed by the costs of caring for HIV patients, as well as the complexities and increasingly high demands of HIV treatments.

Dr Shaun Conway of IAPAC proposed a bold solution in Cairo for a programme of expanded access to enhanced HIV care for HIV-infected individuals in South Africa. The 'Right-toCare Initiative', which is being launched by IAPAC as an HIV Clinician-led Care Management Programme, is based on the principle of risk sharing through capitation contracts within a well-supported and credentialled Preferred Provider Network. IT-enabled clinical decision-support, specialist back-up and co-ordinated individual care management would allow for optimal resource utilisation and enable patient outcomes to be monitored closely and care to be co-ordinated properly.

The programme will use highly innovative approaches to data collection, guarantee payment for clinical services and implement an Intelligent Drug Supply Logistic to ensure that treatments reach and benefit the end-user. The most unusual aspect of this initiative is that it will be 'not-for-profit' - all surplus revenues would be ploughed back into building the capacity to expand care even further and into subsidising treatment.

Dr Conway proposed that 'There are enormous unmet opportunities to strengthen and expand HIV care through developing, and vastly improving the co-ordination of, clinical expertise in generalist HIV medicine. Available resources must be better utilised and this can be achieved through an integrated care management model that leverages Care Provider and Ancillary Services networks. He went on to say that 'This makes Antiretroviral Treatment Access and the provision of HIV Care across the continuum within an "Enhanced Care Package" an attainable possibility, if widely supported and part of a dedicated care delivery effort:
Health care funders and employers increasingly appear to be seeking appropriate care solutions for their members and employees in order to keep these populations healthy, realising the benefits of their investment, which includes the opportunities for secondary prevention.

Notwithstanding the reluctance of pharmaceutical manufacturers to lose their potentially lucrative HIV market, opportunities do exist to negotiate drug discounts based on higher volumes of patients treated or, more ideally, to obtain preferentially priced drugs through international advocacy and other alternative supply mechanisms (although the latter do require political support that must continue to be demanded though strong advocacy by the profession and by civil society - especially those people living with HIV(AIDS).

The Right-to-Care programme will provide innovative ways to enhance clinical decision-support, through guidelinebased computerised tools, accessible specialist advice and incentivised training programmes, so that patients receive the most optimal treatment interventions.

Once implemented, Right-to-Care will facilitate significant growth in the numbers of HIV-infected individuals who will be able to access enhanced, high-quality HIV care across a continuum, which includes making the widespread use of antiretroviral therapy both affordable and effective, while better managing proven preventive interventions and coinfectious diseases.

'Enhanced HIV Care' access will be achieved in the shortest time possible by building and supporting the skills and capacity of health care providers co-ordinated within a strong HIV Clinicians' network, and by leveraging available resources within the South African private health care sector, using these more efficiently, and advocating for international support to make HIV treatments more affordable.

Through this proposed initiative and its affiliated programmes within IAPAC, many more HIV-infected individuals will lead productive lives, remaining healthy for longer, and the spread of HIV infection will be reduced.

To participate in the Right-to-Care Initiative,

or for more information, please contact:

Peter Black, IAPAC Southern Africa Regional Office

Tel: +27(011) 4822630

E-mail:pblack@iapac.org.za

\section{UNAIDS DESCRIBES ITS PROGRESS IN IMPLEMENTING DRUG ACCESS INITIATIVES}

During a panel discussion at the October IAPAC Cairo Conference, moderator Badera Samb from UNAIDS and panelists reviewed the status of the UNAIDS' Drug Access Initiative, which was initiated in 1997. As examples, Samb presented projects carried out in four pilot countries: Chile, Cote d'lvoire, Uganda and Vietnam. These countries had been carefully chosen, based on their relative political and social stability and the level of support of their respective governments. 
The Initiative focuses on widening access to HIV treatment interventions in developing countries. The latest phase of this initiative, which has been named 'Accelerating Access', has involved UNAIDSbrokered negotiations with the 5 large pharmaceutical companies that supply the majority of HIV-related drugs.

The challenge of Drug Access Initiatives is not only to lower the cost of HIV-related drugs, but also to ensure rational prescription and use of the drugs, to implement an adequate and responsive distribution service, and to work with governments to implement and strengthen existing health care systems.

\section{FULL RANGE OF SUPPORT}

Country-level support for the Drug Access Initiative has ranged from entirely private sector to entirely state-sponsored. In Uganda, treatment activities have been privately supported, while in other countries, such as Cote d'lvoire, there has been both private and government support. Chile and Vietnam, have received total government support for costs of therapy.

The Drug Access Initiative has encouraged competition that has pushed down the prices of certain drugs. One confounding factor, however, has been local currency fluctuations, an effect that can also hamper a patient's ability to afford regular treatment.

The achievements so far have shown that the rational use of ART is feasible in developing countries. Other countries such as Senegal, Morocco and Malawi have been encouraged to move forward with access to ART. In the process, countries have learned how to negotiate better prices, but the overall costs of providing HIV care remain daunting to the economies of the Developing World.

Put in context, Switzerland could fund the care of all HIV cases with only $0.06 \%$ of its GNP, while Zimbabwe would have to spend $265 \%$ of its GNP. This shows the enormous gap between rich and poor countries that still needs to be overcome in some concerted way.

Dorothy Ochola, from the Ministry of Health in Uganda, pointed out that Uganda has the capacity to handle up to eight times more patients than proposed by the Drug Access Initiative. Once again, the main barrier is the cost of drugs. New programmes and further negotiations for improving access to treatment for more patients will strengthen this infrastructure and enable greater numbers to be treated, although at much higher cost to the country.

\section{UPDATE ON UNAIDS' CURRENT ACCELERATING ACCESS INITIATIVE}

Jos Perriens of UNAIDS presented details on the essential, intermediate and high complexity care packages recently proposed by the WHO, and he stated the principles for how HIVIAIDS can be tackled.

The UNAIDS Secretariat recently published a call for 'Expressions of interest' to pharmaceutical companies that manufacture opportunistic disease drugs and antiretroviral drugs, as well as to manufactures of HIV-related diagnostic commodities, for them to supply developing countries with their goods at preferential prices.

UNAIDS is currently working with an increasing number of countries, mainly in sub-Saharan Africa, to support them in achieving government commitment and well-planned policies for managing their responses to the epidemic, including how they can improve access to HIV-related treatments.

After these sessions many questions remained, ranging from the effects of poverty and family issues, to controversial policies in some countries requiring patients to pay for their treatment out of their own pockets.
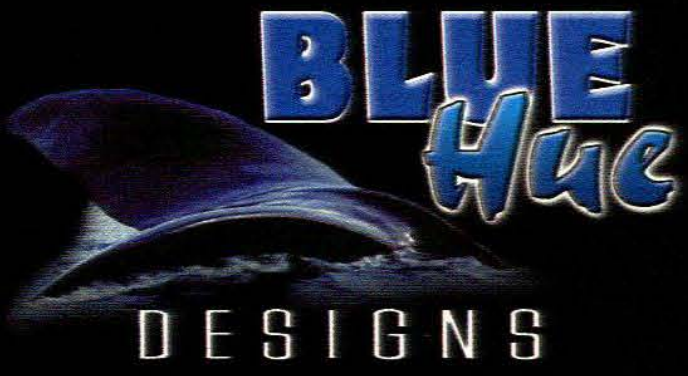

\section{EFFECTIVE}

COMMUNIGAIION

\section{IHROUGH}

\section{DYNAMIL}

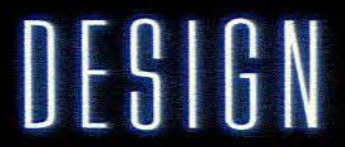

â Ridge Road Hilicrest 3610

KwaZulu-Nata:

Cell: 0835601915

Tel/Fax: 0317651471

E-mail: nadinec o mweb.co.za 